\title{
Motivation for and Benefits from Attending the AP Statistics Reading
}

\author{
Tim Jacobbe ${ }^{1}$, Bradley A. Hartlaub ${ }^{2}, \&$ Douglas Whitaker ${ }^{1}$ \\ ${ }^{1}$ School of Teaching and Learning, University of Florida, Gainesville, Florida \\ ${ }^{2}$ Department of Mathematics, Kenyon College, Gambier, Ohio \\ Correspondence: Tim Jacobbe, School of Teaching and Learning, University of Florida, Gainesville, FL, 32607, \\ USA. Tel: 1-352-273-4232. E-mail: jacobbe@ coe.ufl.edu
}

Received: March 24, 2013 Accepted: April 7, 2013 Available online: May 3, 2013

doi:10.11114/jets.v1i2.135 URL: http://dx.doi.org/10.11114/jets.v1i2.135

\begin{abstract}
This study explores the Advanced Placement ${ }^{\circledR}$ Statistics reading as a source of professional development for teachers. The study was conducted to capture the motivation for and benefits from attending the collective grading. Research has shown that examining student work during professional development has implications for teaching. The premise of this study is that Advanced Placement readings are a context for examining the impact of collective grading of student work. The purpose of the study was to examine the motivation of and benefits for AP Statistics reading participants. The results suggest that analysis of student work may be a method to address teachers' preparation to teach statistics at the level expected by recent reform movements in the field of statistics education.
\end{abstract}

Keywords: statistics education research, professional development, collective grading, Advanced Placement (AP) statistics

\section{Introduction}

\subsection{The Disconnect between Statistics and School Statistics}

The release of the Guidelines for Assessment and Instruction in Statistics Education (GAISE) (Franklin, et al., 2007) highlights the need to address teachers' preparation to teach statistics. Groth (2007) calls attention to the problem of a disconnection between school statistics and the field of statistics. This disconnection is perpetuated by the fact that school statistics is viewed as an extension of mathematics rather than as its own discipline. This often results in an incoherent treatment of statistics in the curriculum, and consequently students are apt to learn statistics as a collection of disconnected tools for analyzing data rather than understanding statistics conceptually (Franklin, et al., 2007). The GAISE framework emphasizes an overarching investigative process as the foundation for statistics instruction rather than specific methods or techniques (Franklin et al., 2007, p. 11). To achieve this curricular coherence, teachers must possess both a broad view of the field and a level of understanding deeper than the students whom they will be teaching (Conference Board of the Mathematical Sciences [CBMS], 2012). Statisticians noted this concern when high school teachers were asked to teach Advanced Placement ${ }^{\circledR}\left(\mathrm{AP}^{\circledR}\right)$ Statistics without much formal preparation in the area. As stated in the GAISE framework, "statistics...is a relatively new subject for many teachers who have not had an opportunity to develop sound understanding of the principles and concepts underlying the practices of data analysis they are now called upon to teach" (Franklin, et al., 2007, p. 5). This is reinforced by the recommendation in the Mathematical Education of Teachers II that pre-service teachers for middle school and high school level take full courses in statistics, and that pre-service elementary school teachers be exposed to the statistical content the will be taught in the middle school (CMBS, 2012). The obvious method of helping high school teachers become more prepared to teach statistics is professional development. One common way this professional development is provided is through one- and two-day workshops sponsored by the College Board ${ }^{\circledR}$, in-service training, and summer institutes. These workshops provide teachers with resources and content about pedagogy. Another, perhaps more promising professional development method, is the collective analysis of student work at the AP Statistics reading. The reading has many unique features that attract a wide variety of high school teachers and college instructors. 
Research focused on the use of student work during professional development has been gaining momentum over the past decade (Shaughnessy, 2006). Most of these studies involve teachers exploring their own students' work (e.g., Cameron, Loesing, Rorvig, \& Chval, 2009; Kazemi \& Franke, 2004). In these studies researchers documented that teachers showed increases in their insight regarding their students' thinking. Researchers posit that these insights will then have profound impacts on teaching. Teachers' motivation to explore their own students' work is obvious; however this study explores the motivation for and benefits to teachers for exploring the work of students other than their own at an AP Statistics reading.

\subsection{Description of the AP Statistics Reading}

The AP Statistics exam was first administered by the College Board in 1997. As with other AP exams, the multiple-choice section is scored electronically whereas the free-response section is scored manually at a reading. The AP Statistics reading is carried out by both high school teachers and college instructors who are called "readers." Due to steady linear increases in the number of exams taken each year, the number of readers/leaders required to grade the exams has risen from a total of 47 in 1997 to 537 in 2009 (C. Franklin, personal communication, April 5, 2010).

Generally, each reader grades two of the six free-response questions on the exam. Readers are provided two-hours of training for each question they grade during which they are presented with the rubric, pre-scored responses, and the opportunity to practice grading additional sample responses to ensure consistency in applying the rubric, e.g. to increase inter-rater reliability. Recruiting over 500 readers to dedicate an entire week to score student responses using a rubric they did not create was initially not an easy task. This is despite the fact that readers are paid a nominal fee for their work. However, in recent years applicants have been turned away due to an increased interest in this professional development opportunity. The research questions for this study were: Is the motivation to participate in the AP Statistics reading the same for high school teachers and college instructors? Does motivation for attending the AP Statistics reading change over time? What benefits do high school teachers and college instructors report from attending the AP Statistics reading? Are the benefits the same for each population?

The potential benefits from attending an AP Statistics reading result from transformation through participation as described by Rogoff's (1997) concept of peripheral participation. By transformation through participation, “...a person develops through participation in an activity, changing to be involved in the situation at hand in ways that contribute both to the ongoing event and to the person's preparation for involvement in other similar events" (Rogoff, 1997, p. 271). At the AP Statistics reading individuals make contributions to the reading by grading students' papers; however they receive benefits to their own teaching, learning, and assessment skills.

The value of attending an AP reading for professional development has been documented before. Kennedy (1999) discussed the professional development he received from attending an AP reading related to calculus. According to Kennedy, "... one of the most professional benefits for AP readers is the opportunity for calculus teachers to learn more about calculus" (p. 346). He goes on to say, "... those of us who have read AP calculus papers over the years have also learned that the simplest of problems can have remarkable subtleties buried just beneath the surface" (p. 346). The AP readings can therefore be viewed as extremely large professional development activities. According to Grundy and Robison (2004) there are two motivating factors for attending professional development - systemic and personal. Since attendance at an AP Statistics reading is done without systemic impetus from school districts it can be argued that readers attend out of a personal drive. The question that this study attempted to answer is what motivates that personal drive.

The main activity at the AP Statistics reading involves transformation through participation in the examination of student work. Several studies have reported on the benefits from the use of student work during professional development activities (e.g., Cameron, Loesing, Rorvig, \& Chval, 2009; Kazemi \& Franke, 2004; Krebs, 2005).

\subsection{Value of Examining Student Work}

Kazemi and Franke (2004) worked with a group of 10 teachers as they explored their own students' work during a professional development activity. Prior to professional development meetings, teachers administered common questions to their students and selected representative samples to bring to the meeting. In order to explore changes in teachers as a result of this experience, researchers coordinated meetings for the examination of student work as well as made periodic visits to the teachers' classrooms. Kazemi and Franke noted two main findings regarding the impact of examining student work. First, participation in this activity focused teachers' attention on children's thinking. Secondly, this refocusing impacted the teachers' approaches to instructional decision-making based on the use of the lessons learned. This connection and translation into practice seems 
more likely when teachers explore work from their own students. The researchers in this study wondered what describes the motivation and benefits teachers receive from the examination of other students' work.

Krebs (2005) conducted a study with 20 teachers as they considered work on a mathematics task from 3 pairs of students that were not their own. The design of the professional development involved three steps. First, teachers worked the mathematical tasks themselves and discussed expected issues that might arise for students as they solved the problems. Next, students' work was explored and discussed in relation to those anticipated issues that might arise. Finally, teachers viewed videotapes of the pairs of students as they solved the problems. Krebs concluded that this professional development experience emphasized the importance of teachers' considering multiple sources of evidence for the purpose of assessment, which may have implications for teachers' practice.

The AP Statistics reading does not involve the exploration of teachers' own students' thinking, but rather that of a sample of students who took the exam. It also does not involve the exploration of information from multiple sources yet it is reported by Kennedy (1999) that attending an AP reading is a powerful professional development experience for teachers.

\section{Method}

\subsection{Sampling Procedures}

This study examined data collected from readers on the $5^{\text {th }}$ day (out of 7) at the 2008 AP Statistics reading in Louisville, KY. A survey with 5 items was given to the 516 readers and leaders in attendance. The survey was distributed to the leaders of each room of readers, and the leaders encouraged the readers to take the survey. In an attempt to increase the response rate for the surveys, individuals were informed that 10 completed surveys would be randomly selected to receive $\$ 20$ gift cards. All 516 readers in attendance were invited to take the survey. Of these, 183 high school teachers and 193 college instructors completed the survey for a response rate of $73 \%$.

\subsection{Description of Survey}

The first item asked participants to indicate the number of years they had attended an AP Statistics reading. Note that this was the $12^{\text {th }}$ year for the AP Statistics reading. The second and third items addressed readers' motivation for attending the reading across four categories: (1) Making extra money; (2) Meeting fellow statistics teachers; (3) Professional development; and (4) Other. If participants selected "Other," they had the opportunity to explain the motivation. It was hypothesized that the financial incentive would have similar motivation for high school teachers and college instructors.

On the second item, participants rated their motivation for attending their first AP Statistics reading on a 4-point scale ranging from 1 (not influential) to 4 (very influential).

Readers who had attended at least one prior reading were also asked to respond to the third item. This item explored whether the motivation for attending the first reading differed from motivation for attending subsequent readings. There were 133 high school teachers and 121 college instructors who responded to this third item.

The fourth item asked readers to indicate the level of benefit they receive from attending the reading across four categories: (1) Teaching Strategies; (2) Statistical Content Knowledge; (3) Networking for Future Collaboration; (4) Understanding Common Student Misconceptions; and (5) Other. Respondents were asked to provide a rating in each category on a 4-point scale ranging from 1 (no gain) to 4 (greatest gain). It was hypothesized that high school teachers would receive more benefit in the area of Statistical Content Knowledge than the college instructors.

The final (fifth) item asked readers to rank order the impact of the reading in terms of their learning from three areas: assessment, statistics content, and teaching. For this ordinal ranking, 1 represented the area they learned the most and 3 represented the area they learned the least.

\section{Results}

\subsection{Overall Summary Statistics (Results from Item 1)}

The mean number of years attending an AP Statistics reading for high school teachers was 3.76 with a standard deviation of 3.03 whereas the mean number of years for college instructors was 3.72 with a standard deviation of 3.19. Table 1 summarizes the results of the comparisons between high school teachers and college instructors. The response categories of "Other" for items 2,3, and 4 are not included in the results here. Readers did not select this very often and responses varied extensively. The most common alternative reason provided was attending at the suggestion of a close colleague. 
Table 1. Comparison of High School and College Responses to Survey

\begin{tabular}{|c|c|c|c|c|c|c|c|c|c|}
\hline \multirow[b]{2}{*}{ Item } & \multirow[b]{2}{*}{ Variable } & \multicolumn{3}{|c|}{ High School } & \multicolumn{3}{|c|}{ College } & \multirow[b]{2}{*}{$t$} & \multirow[b]{2}{*}{$p$} \\
\hline & & $n$ & $M$ & $S D$ & $n$ & $M$ & $S D$ & & \\
\hline & $\mathrm{MM}$ & 182 & 2.42 & 1.11 & 189 & 2.63 & 1.08 & 1.91 & .06 \\
\hline \multirow[t]{3}{*}{2} & MFT & 183 & 3.37 & 0.75 & 191 & 2.98 & 0.94 & -4.42 & $<.001$ \\
\hline & PD & 183 & 3.69 & 0.68 & 192 & 3.02 & 0.98 & -7.77 & $<.001$ \\
\hline & MM & 133 & 2.41 & 1.07 & 118 & 2.53 & 1.04 & 0.90 & .37 \\
\hline \multirow[t]{4}{*}{3} & MFT & 133 & 3.53 & 0.70 & 121 & 3.26 & 0.93 & -2.59 & .01 \\
\hline & PD & 133 & 3.77 & 0.59 & 121 & 3.15 & 0.98 & -6.02 & $<.001$ \\
\hline & $\mathrm{T}$ & 178 & 2.98 & 0.72 & 184 & 2.69 & 0.87 & -3.50 & .001 \\
\hline & $\mathrm{C}$ & 178 & 3.22 & 0.76 & 185 & 2.52 & 0.95 & -7.76 & $<.001$ \\
\hline \multirow[t]{3}{*}{4} & $\mathrm{~N}$ & 178 & 3.08 & 0.81 & 184 & 2.78 & 0.87 & -3.36 & .001 \\
\hline & $\mathrm{M}$ & 178 & 3.56 & 0.68 & 184 & 3.05 & 0.84 & -6.35 & $<.001$ \\
\hline & A & 181 & 1.54 & 0.70 & 184 & 1.41 & 0.69 & -1.85 & .07 \\
\hline \multirow[t]{2}{*}{5} & $\mathrm{C}$ & 181 & 2.14 & 0.78 & 185 & 2.36 & 0.71 & 2.81 & .005 \\
\hline & $\mathrm{T}$ & 181 & 2.32 & 0.77 & 184 & 2.22 & 0.71 & -1.26 & .21 \\
\hline
\end{tabular}

Note. Item refers to item on survey. $\mathrm{MM}=$ Making Money; MFT $=$ Meet Fellow Teachers; $\mathrm{PD}=$ Professional Development; $\mathrm{T}=$ Teaching $; \mathrm{C}=$ Content; $\mathrm{N}=$ Networking; $\mathrm{M}=$ Misconceptions; $\mathrm{A}=$ Assessment.

\subsection{Significance Tests}

All analyses were performed using SPSS 19 for Mac using an alpha $(\alpha)$ level of 0.05 . Confidence intervals are given at the $95 \%$ confidence level.

\subsubsection{Results for Items 2 and 3}

As expected, the average ratings for money were not significantly different for these two groups of teachers, although the $p$-value is 0.06 for readers who were attending for the first time. College instructors were slightly more motivated by the monetary benefit of attending the reading than high school teachers. New high school teachers rated both meeting fellow teachers, $p<0.001$, and professional development, $p<0.001$, significantly higher than college instructors. The results were similar for experienced readers for meeting fellow teachers, $p=0.01$, and for professional development, $p<0.001$.

To determine whether readers' motivation for attending their first and subsequent reading sessions differed, paired comparisons of their ratings were examined (Table 2).

Table 2. Paired comparison for responses of experienced teachers to Item 2 and Item 3

\begin{tabular}{llllll}
\hline Variable & $N$ & $M$ & $S D$ & $S E$ & $95 \% \mathrm{CI}$ \\
\hline MM & 248 & 0.0121 & 0.5435 & 0.0345 & $(-0.06,0.08)$ \\
MFT & 253 & 0.1581 & 0.6352 & 0.0399 & $(0.08,0.24)$ \\
PD & 253 & 0.1304 & 0.6194 & 0.0389 & $(0.05,0.21)$ \\
\hline
\end{tabular}

Note. $\mathrm{CI}=$ confidence interval. $\mathrm{MM}=$ Making Money; MFT = Meet Fellow Teachers; PD $=$ Professional Development.

These results illustrate that the effect of money does not differ based on whether the readers are new or experienced. The $95 \%$ confidence interval for the mean difference in ratings (Item 3 - Item 2) is [-0.06, 0.08] and includes zero. The primary motivators for attending the reading, both of which have a statistically significant effect, are meeting fellow teachers and professional development. The $95 \%$ confidence interval for the mean 
difference in meeting fellow teachers is $[0.08,0.24]$ and the interval for the mean difference in professional development is $[0.05,0.21]$.

\subsubsection{Results for Item 4}

Turning to the comparisons for knowledge gained (Item 4), the high school teachers have significantly higher averages than college instructors for every category. Independent sample $t$-statistics illustrate that high school teachers reported gaining more knowledge in teaching strategies, $p=0.001$, statistical content knowledge, $p<0.001$, networking for future collaboration, $p=0.001$, and understanding of common student misconceptions, $p<0.001$, than college instructors. Both groups reported learning the most about students' misconceptions. As expected, the greatest difference between high school teachers and college instructors was in the area of statistics content. This result reinforces that the analysis of student work presents high school teachers with an opportunity to learn some of the advanced content necessary to teach AP Statistics.

\subsubsection{Results for Item 5}

Finally, the two groups were asked to rank their knowledge gained in the areas of assessment, statistics content, and teaching from highest to lowest. Once again, the high school teachers reported significantly greater knowledge gained in the area of statistical content, $p=0.005$. The mean rankings for assessment, $p=0.07$, and teaching, $p=0.21$, were not significantly different.

A Friedman's test for a block design with subject (participant) as the blocking factor was used to further analyze responses to the fifth item. Friedman's test is a nonparametric statistical test that is similar to Repeated Measures ANOVA and can be used with ordinal data. Recall for this ordinal ranking, 1 represented the area they learned the most and 3 represented the area they learned the least. The results from this analysis clearly indicate a statistically significant difference in the three areas $Q=149.5, p<0.0001$. In fact, the estimated medians show that assessment $(M d n=1.33)$ receives significantly higher ratings than content $(M d n=2.00)$ and teaching $(M d n$ $=2.67)$. The estimated means illustrate similar effects, $F=93.71, p<0.001$, with the average assessment $(M=1.48)$ rank being significantly higher than the average ranks for content $(M=2.25)$ and teaching $(M=2.27)$. These results indicate that readers feel they learn the most about assessment, followed by content, and finally teaching. This suggests that many readers may not realize that learning about common student misconceptions (as reported in the analysis of responses to item 4) has direct implications for teaching.

\section{Discussion}

\subsection{Implications for Professional Development}

Based on the statistical results presented above, we can say that the financial motivation appears constant across both populations of readers: high school teachers and college instructors. Furthermore, the financial benefit has the same motivation on both new and returning readers. The benefits of meeting fellow teachers and professional development were more motivational for high school teachers and experienced readers. Combined with the differences between high school teachers and college instructors in the area of statistical content knowledge, these results suggest that the AP reading is providing an effective form of professional development for high school teachers. Furthermore, the results of the analysis of Item 5 indicate that teachers may not understand that learning about common student misconceptions has direct implications for teaching, instead focusing on the more direct benefits of the professional development experience such as assessment and content knowledge.

\section{Conclusion}

\subsection{Collective Grading of Student Work as Professional Development}

This study reveals substantial self-reported benefit from attending the AP Statistics reading for high school teachers. With the increased expectations set forth in the GAISE framework, there is a substantial need to improve the teaching of statistics at all levels. This study suggests that the analysis of student work is a promising strategy for professional development to accomplish this goal.

As discussed by Kazemi and Franke (2004), participation in a collective grading allows the participants to focus on students' thinking. Further, these authors explored the impact that collective grading experiences had on teachers' instructional decisions.

\subsection{Limitations}

The current study only investigated readers' responses to a survey. Because the responses to "other" choices were excluded, it is possible that other motivating factors for high school teachers and college instructors exist that could not be analyzed in a quantitative format. Furthermore, all AP readings are different, and the results of this study cannot be directly applied to other large, national exam grading sessions, regardless of subject. 


\subsection{Future Research}

The AP readings are a natural medium to explore the impact of analyzing student work as a professional development activity. Further research should explore the motivations for attending the reading for individual teachers in an in-depth manner as well as attempt to follow readers into their schools in order to capture the transfer that occurs from what they gain from attending the reading to what transpires in the classroom.

\section{References}

Cameron, M., Loesing, J., Rorvig, V., \& Chval, K. (2009). Using student work to learn about teaching. Teaching Children Mathematics, 15, 488-493.

Franklin, C., Kader, G., Mewborn, D., Moreno, J., Peck, R., Perry, M., \& Scheaffer, R. (2007). Guidelines for assessment and instruction in statistics education (GAISE) report. Alexandria, VA: American Statistical Association.

Groth, R. E. (2007). Toward a conceptualization of statistical knowledge for teaching. Journal for Research in Mathematics Education, 38, 427-437.

Grundy, S., \& Robison, J. (2004). Teacher professional development: Themes and trends in the recent Australian experience. In C. Day \& J. Sachs (Eds.), International handbook on the continuing professional development of teachers (pp. 146-166). Berkshire, UK: Open University Press.

Kazemi, E., \& Franke, M. L. (2004). Teacher learning in mathematics: Using student work to promote collective inquiry. Journal of Mathematics Teacher Education, $203-235$. http://dx.doi.org/10.1023/B:JMTE.0000033084.26326.19

Kennedy, D. (1999). Things I have learned at the AP reading. The College Mathematics Journal, 30, $346-355$. http://dx.doi.org/10.2307/2687537

Krebs, A. S. (2005). Analyzing student work as a professional development activity. School Science and Mathematics, 105, 402-411. http://dx.doi.org/10.1111/j.1949-8594.2005.tb18060.x

Rogoff, B. (1997). Evaluating development in the process of participation: Theory, methods, and practice build on each other. In E. Amsel \& A Renninger (Eds.), Change and Development (pp. 265-285). Hillsdale, NJ: Erlbaum.

Shaughnessy, J. M. (2006). Student work and student thinking: An invaluable source for teaching and research. In A. Rossman \& B. Chance (Eds.), Proceedings of the Seventh International Conference on Teaching Statistics: Working cooperatively in statistics education. Salvador, Brazil. Voorburg: The Netherlands: International Association for Statistical Education and the International Statistical Institute.

\section{$(\mathrm{cc}) \mathrm{BY}$}

This work is licensed under a Creative Commons Attribution 3.0 License. 